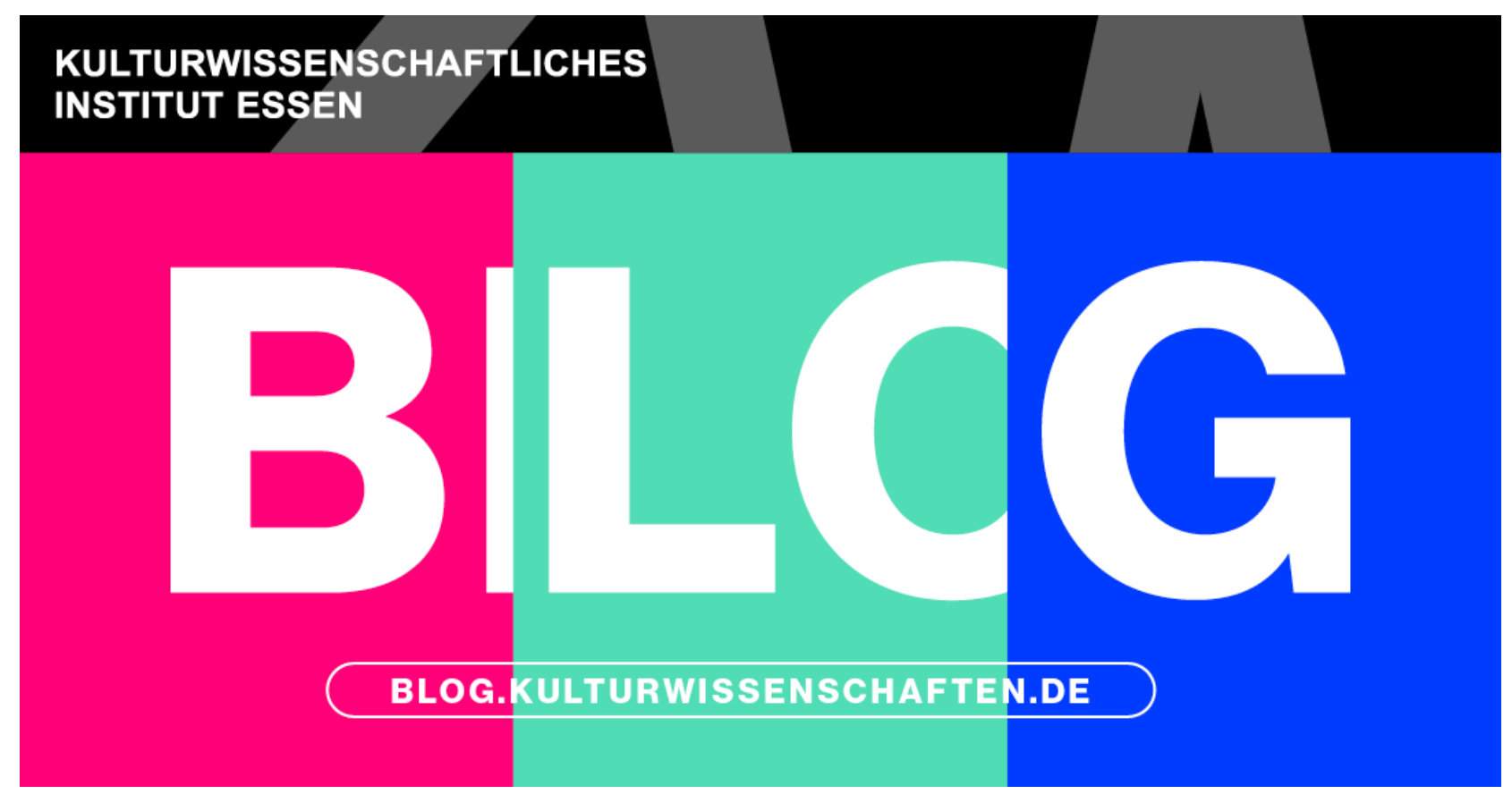

\title{
When Themes Come True Why Board Games are like Theme Parks
}

Von: Péter Kristóf Makai

We seek meaning in our lives; we want our actions to matter. Games of all sorts, however, are among those activities where the consequences of our actions only play out in the world of the game, allowing us to experiment with different strategies in order to overcome our opponents without fear of causing a catastrophic mishap. While exchanging a couple of pieces of cardboard for wooden blocks to push a player token five centimetres to the right might spell victory at the final scoring of a complex board game, this is also frivolous in some fundamental way. Even so, tabletop games endow such trivial actions with meanings that make a marathon gaming session memorable - and they do it through theming. 


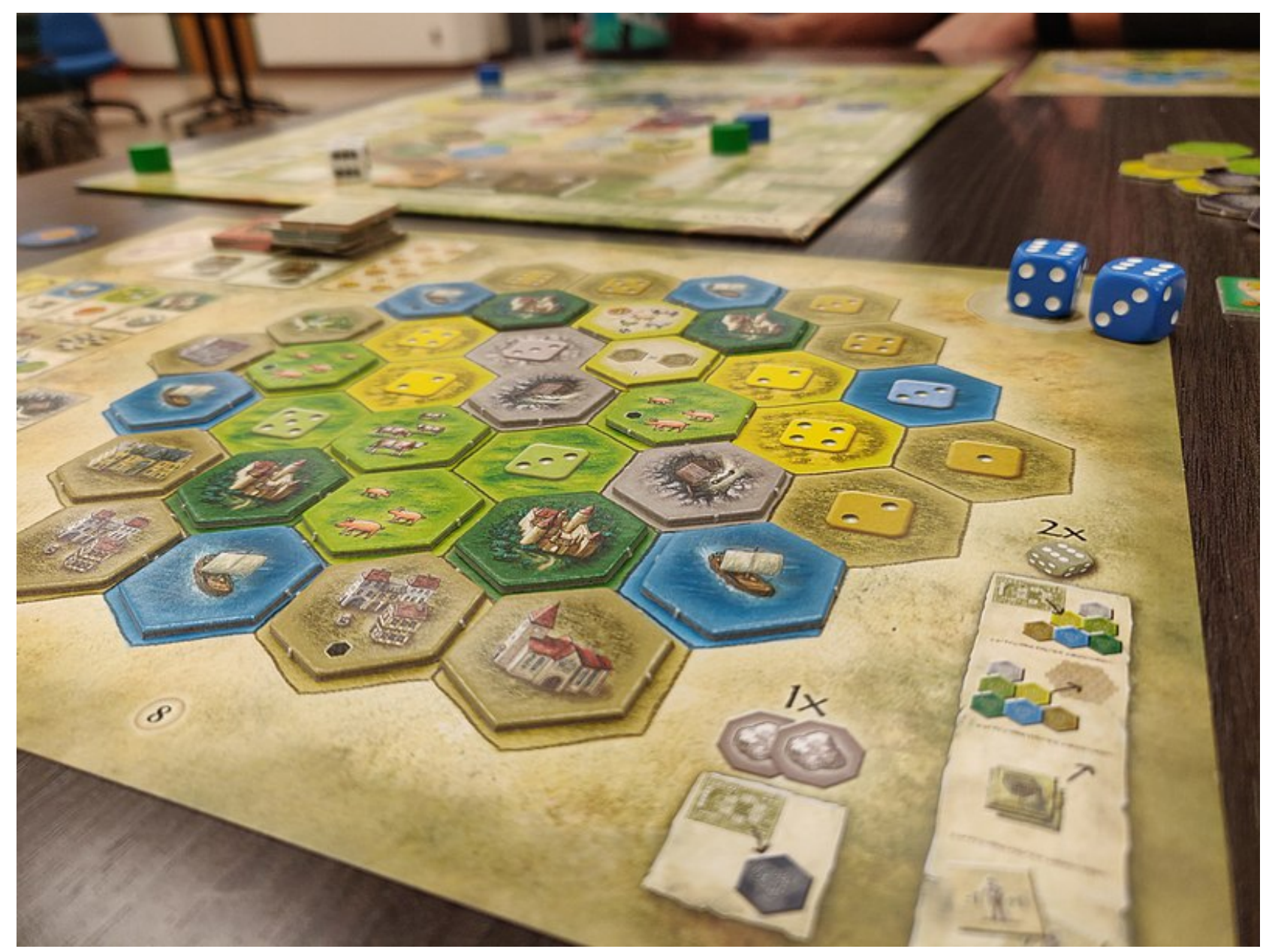

Image 01: Castles of Burgundy (Creative Commons Universal Public Domain)

When we speak of themes, we tend to think of abstract, symbolic messages that echo in media and resonate throughout history, such as "love conquers all", "crime does not pay" or "lack of communication kills". Similarly, a musical theme or a leitmotif can be associated with a character even when the person is neither on stage nor on screen. However, the historical development of theming is a story of how the nineteenth century's technological progress was put into the service of entertainment.

After the 1851 Great Exhibition in London, cities vied to wow the world with new inventions and stunning architecture that showed the might of nations. The Ferris wheel, anthropological villages, steam carousels and many mechanical contraptions were soon finding their ways into amusement parks all debuted at fairs. Many world's fairs were also united under the banner of a catchphrase serving as the fair's theme, such as "Century of Progress" (Chicago 1933) or "Building the World of Tomorrow" (New York 1939). These prepared visitors for ways to interpret the fair's many wonders. And while amusement parks would continue to add new twists to rollercoasters, it took theme parks such as Knott's Berry Farm or Disneyland to marry the stylised architecture of anthropological villages and the kinaesthetic thrills of amusement rides in the creation of fully realised, themed lands that tell a story. 


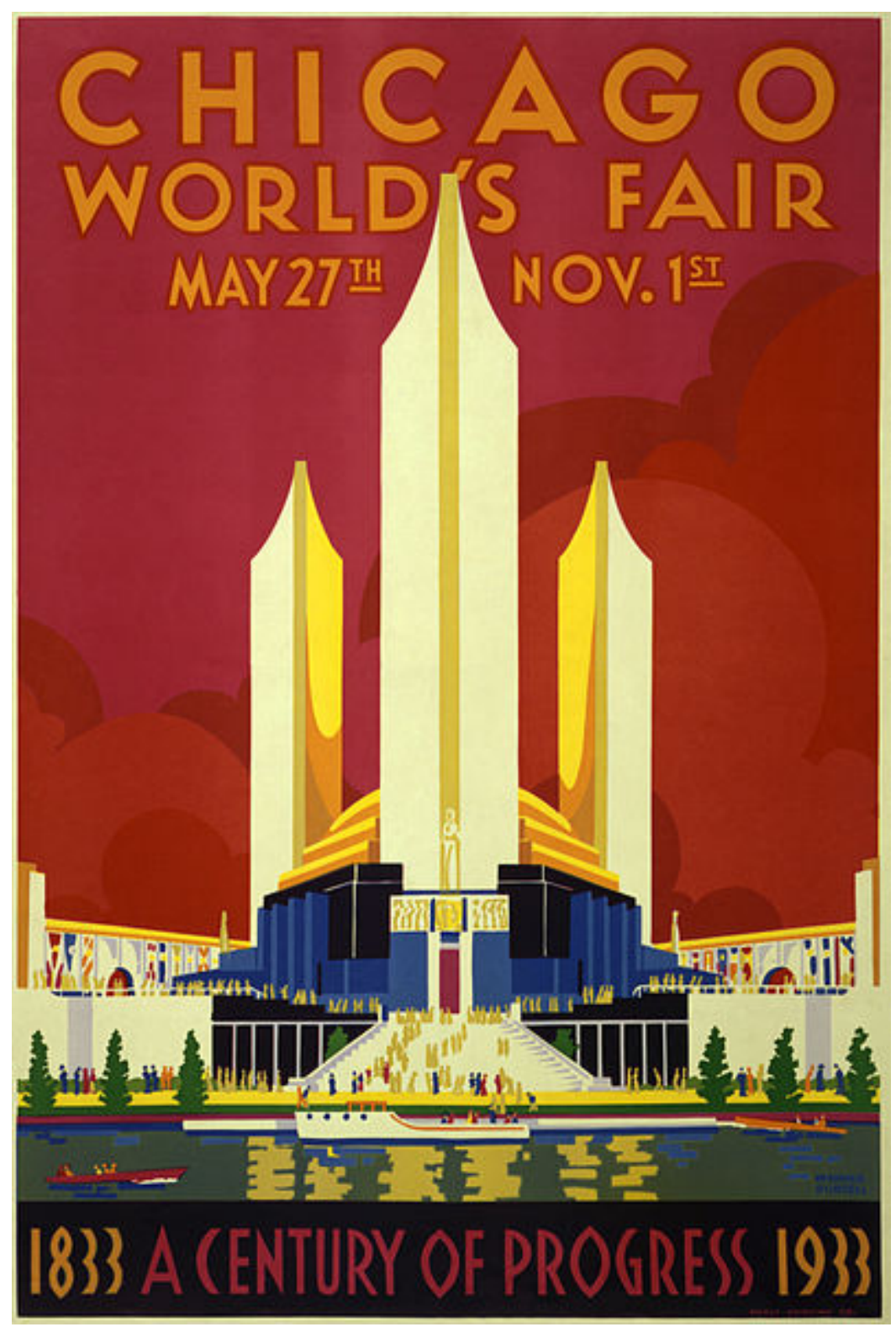

Image 02: Poster of the 1933 Chicago World's Fair (Source: Wikimedia, Public Domain)

Theming creates a sense that the customer walks into another world, where every object in the built environment contributes to an on-going narrative or ambience. For example, the themed land Harambe in Disney's Animal Kingdom is made to resemble an East African port village, telling the story of the preservation of wildlife from poaching and habitat destruction. It does so through architecture, ride design, landscaping, signage and the performance of its employees. Theming reaches far beyond theme parks, however: a restaurant styled to look like a 1920s speakeasy, a hotel with rooms decorated with rockand-roll imagery, or a casino with Egyptian pyramids and mummies are all possibilities for themed entertainment. 


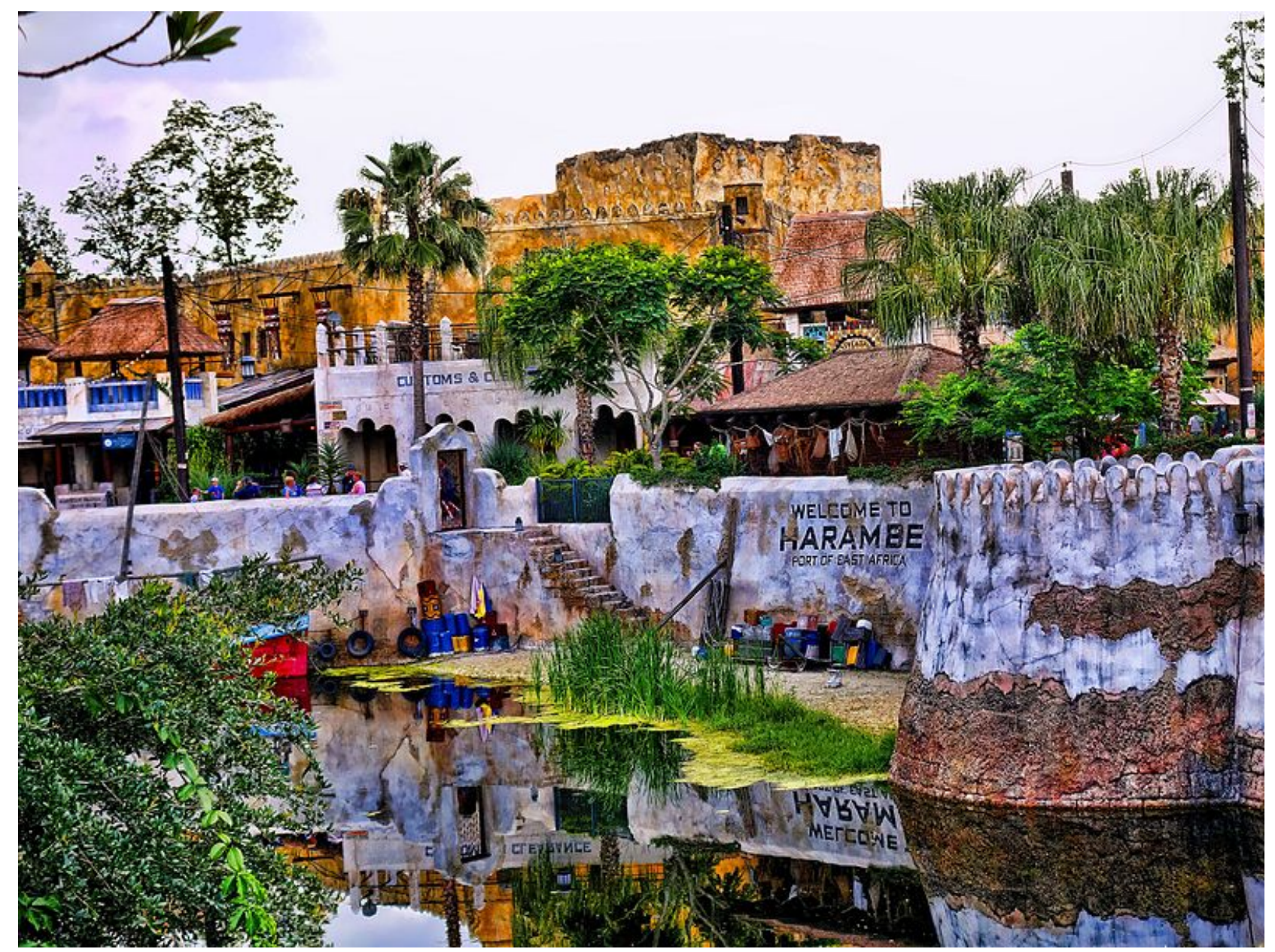

Image 03: The town of Harambe in Disney's Animal Kingdom, 1998 (Source: Wikimedia, Creative Commons Attribution 2.0 Generic Licence)

Board games also have a history. of edifying messages that serve as themes. Gyan chaupar (better known as snakes and ladders in the West) is a dice game that teaches about spiritual enlightenment and the freedom from rebirth. Science in Sport or the Pleasures of Astronomy is a game developed in 1804 by John Wallis extolling the virtues of stargazing. Despite rich opportunities for storytelling, theming can also serve as little more than window dressing on the same game mechanic. A famous example is The Royal Game of Goose, one of the earliest styles of board games (roll-and-move or race games), which has been reskinned so many times that its variations fill a whole book. 


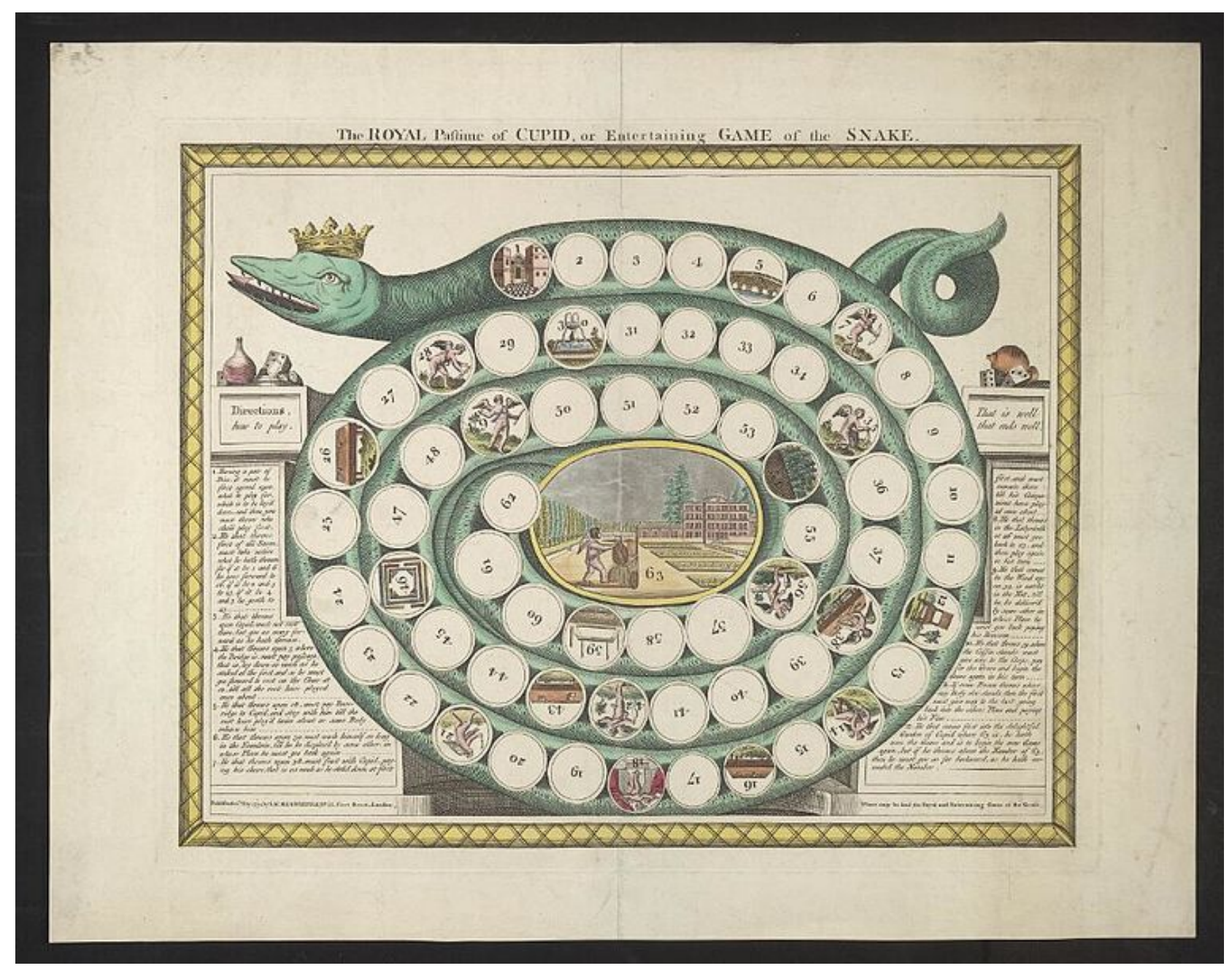

Image 04: "The Royal Pastime of Cupid, or Entertaining Game of the Snake", 1794, a retheming of the Royal Game of Goose (Source: Wikimedia, Creative Commons Attribution 4 Licence)

In general, board games are playful systems designed to simulate a small, abstracted world in which players can contest or cooperate with each other, and their actions are mediated through a rule system that defines what they can do and with what consequence. These actions are grouped together as mechanics according to how they translate to the game state. Mechanics might describe, for example, that the personshaped wooden cubes called "meeples" represent players, or that one can exchange brown resource cubes for a particular amount of victory points, or that one can gain resource cubes by bidding for them with the game's currency. Mechanics make players think hard about how to maximise the utility of their limited influence on the game state, ${ }^{1}$ but they do not speak to the imagination. While theme-focused and mechanics-focused design are not mutually exclusive, gamers do not purchase a $€ 100$ box simply to rearrange cards, cubes and tokens: they want to feel like they are spice magnates, fantasy heroes or private investigators. 


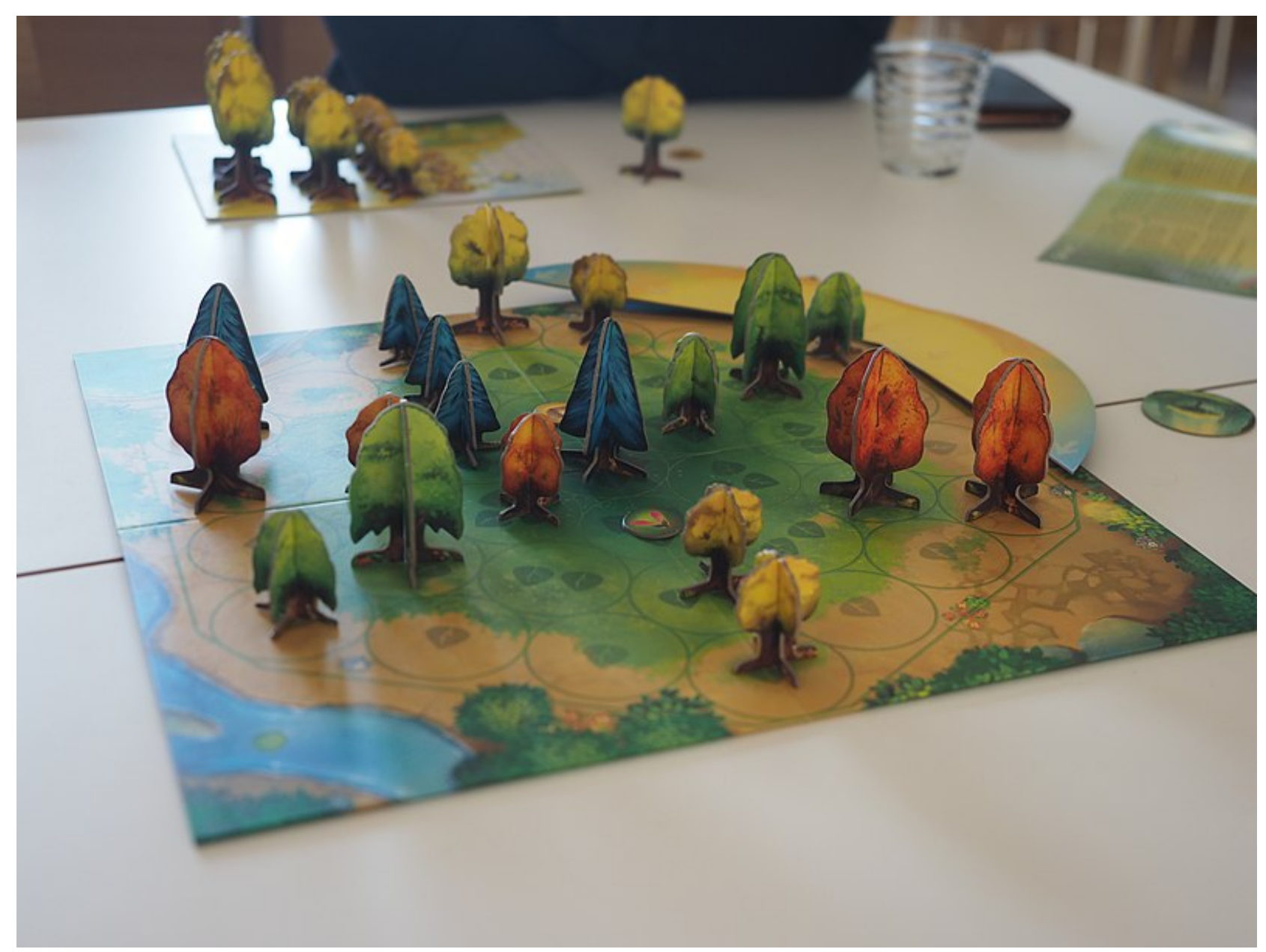

Image 05: A game of Photosynthesis, where players must grow mighty trees from humble seeds (Source: Wikimedia, Creative Commons Share Alike Licence)

Themes are the basis of stories the designers want to tell through the mechanics and the artwork of a game. Everything from the way the game pieces are shaped to the decorations on the board, or from the box art to the text on a playing card, can reinforce or subvert messages intended to enhance gameplay. Themes may be very abstract, like chess representing medieval conflict, or very specific, such as the German industrial revolution in Thomas Spitzer's The Ruhr: A Story of Coal Trade. Many themes are recognisable from genres of popular fiction, such as fantasy, science fiction or colonial adventure, while others relate to specific intellectual property, like The Lord of the Rings: Journeys in Middle-earth or Battlestar Galactica.

Themes not only contextualise play, but also directly affect the game's appeal, and therefore sales.

\section{As Stewart Woods explains:}

The emphasis on historical and economic themes is a significant trait of [E] urogames, as it affects their positioning in the marketplace. Unlike Anglo-American games that often focus on niche interests (historical conflict, science fiction, etc.), [E] urogame themes are arguably more accessible to a broader market. While a sustained interest in fictional genres, such as science fiction and fantasy, is perhaps a requirement for enjoying a game 
tightly themed around these settings, the loose application of generic subject matter, such as history, business and the natural world, requires little player investment in the thematic background in order to engage with the game. ${ }^{2}$

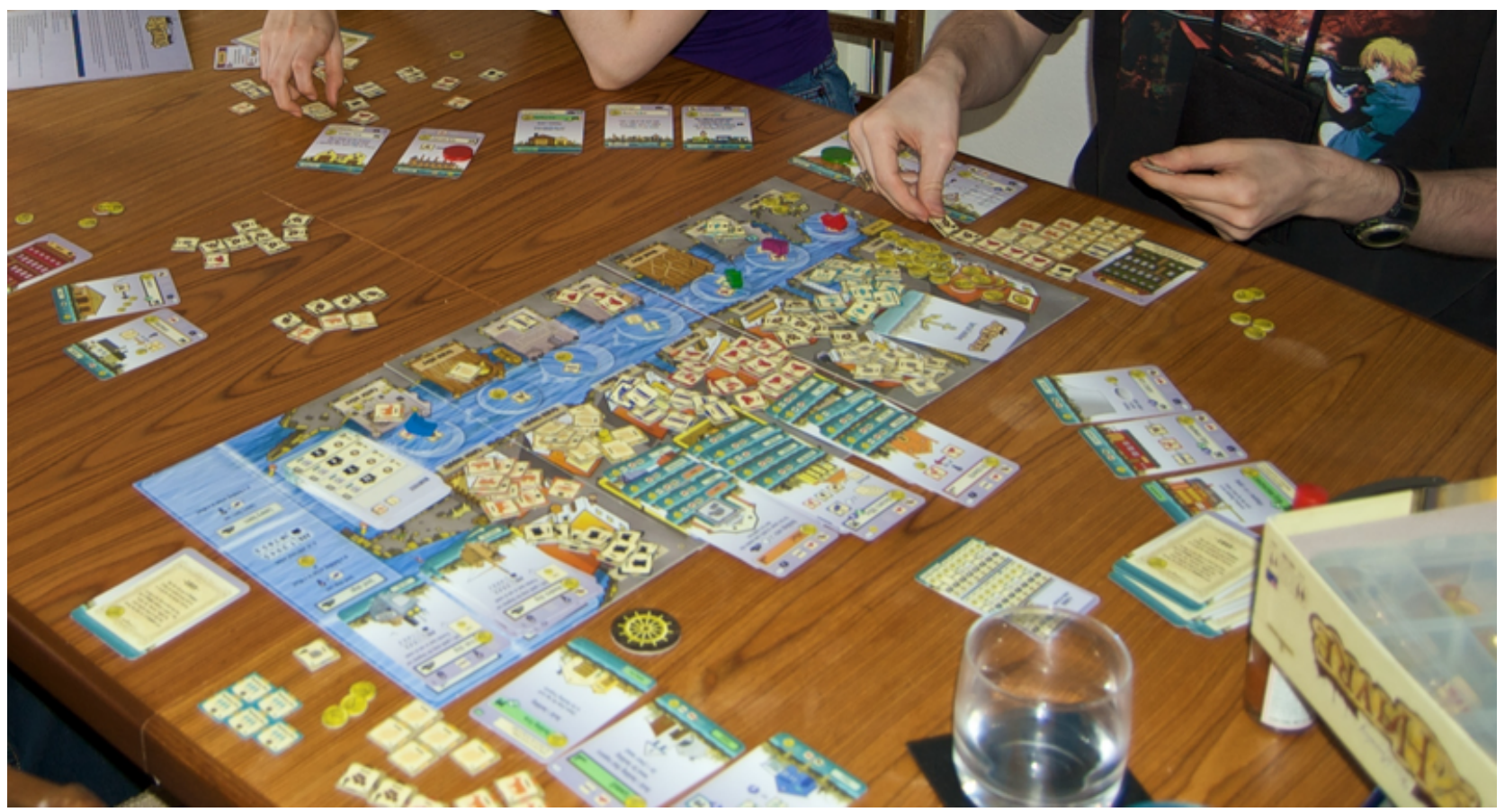

Image 06: Le Havre, a Eurogame with a historic and economic theme about building up the docks of Le Havre (Source: Wikimedia, Creative Commons Attribution-Share-Alike 2.0 Generic Licence)

Likewise, theme parks exclude certain niche themes, taboo subjects and historically unappealing topics (office life, sexuality, violence, the horrors of colonial history, to name just a few) in order to promote fun for the whole family. One could argue that, more than anything, accessible family entertainment is what ties together board games and theme parks. Just as in the parks, the themes of board games place the players in virtual storyworlds, using narrative cues to frame game mechanics and thereby motivate the players' actions.

Curiously, theme park designers often talk in playful terms about how they create rides. Disney Imagineer John Hench reportedly claimed: "we offer adventures in which you survive a kind of personal challenge... But in every case, we let you win" (emphasis mine). Dark ride narratives fit into the overarching story of the land but provide individual storylines to beloved characters that the riders participate in within the confines of the linear, on-the-rails narrative of the rides.

Similarly, there has been a trend in board game design to use stronger, more developed storylines for the characters the players embody to provide deeper engagement. One example is that of so-called "legacy games". For example, Pandemic Legacy puts you in the shoes of a team of public health experts, and tasks you and your friends with stopping a killer virus ravaging the globe. The game is designed so that the gameworld and the player characters are permanently changing over the course of play: you rip up cards, place stickers on the board, and new game mechanics are introduced as your player characters gain quantifiable experience, new equipment or new abilities with every new game you play. 


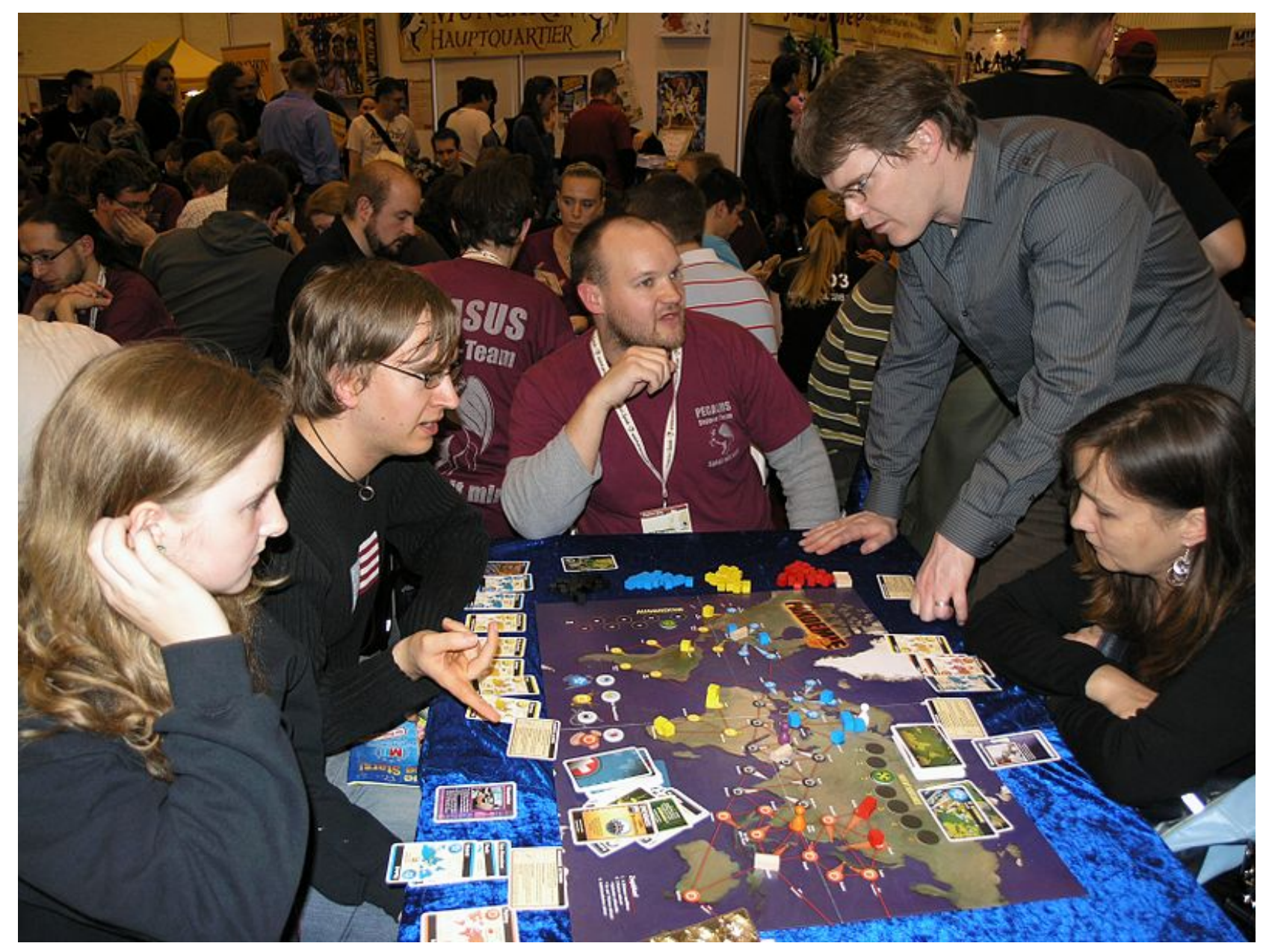

Image 07: A game of Pandemic at the 2008 Spielmesse Essen (Source: Wikimedia, Creative Commons Attribution-Share Alike 3.0 Unported)

As Marco Arnaudo observes

Character evolution is actually so important, in thematic games, that sometimes it is the main driving factor of a design. In some cases, most of gameplay may consist of leading one's characters through a series of ordeals in the pursuit of the items and skills that are required to confront a final challenge. When this occurs, gameplay may acquire the structure of a Bildungsroman of sorts. ${ }^{3}$

In games such as these, themes dominate the experience, and even transform the players themselves as they overcome the challenges of the game.

Theming, admittedly, must work differently in board games and parks. For one, the worlds of board games are predominantly planar (two-dimensional), where we oversee the abstract action from high above. In contrast, theme parks are fully realised in threedimensional space, where patrons are in the middle of the action. They also offer raw, kinaesthetic thrills, and use smells, sounds or the splash of water to immerse guests into their environments. Board games offer few of these, opting instead to use visual and textual abstractions, as well as the ready tactility of the game pieces to draw players in. Nonetheless, the similarities are also substantial: whether as abstract as colonising an uninhabited island (The Settlers of Catan) or as specific as becoming Baker Street Irregulars to figure out the identity of Jack the Ripper (Sherlock Holmes Consulting Detective: Jack the Ripper \& West End Adventures), themes invite the players into 
universes of the imagination. The themes in both games and amusement parks construct storyworlds, create expectations of entertainment and instruct us how to behave. They influence the ideologies of the stories told through actions, so, for example, a game about colonialism would suggest some form of a virgin land ready to be discovered by the interactors, resources to be exploited, the joys of civilization to be built and benighted natives as antagonists. They are highly complex assemblages of semiotic and material components that retrain the mind through the learning, adoption and execution of rules that govern interactions within the world of the game or the park. That is the legacy of theme parks, and a continued source of inspiration to designers in every discipline.

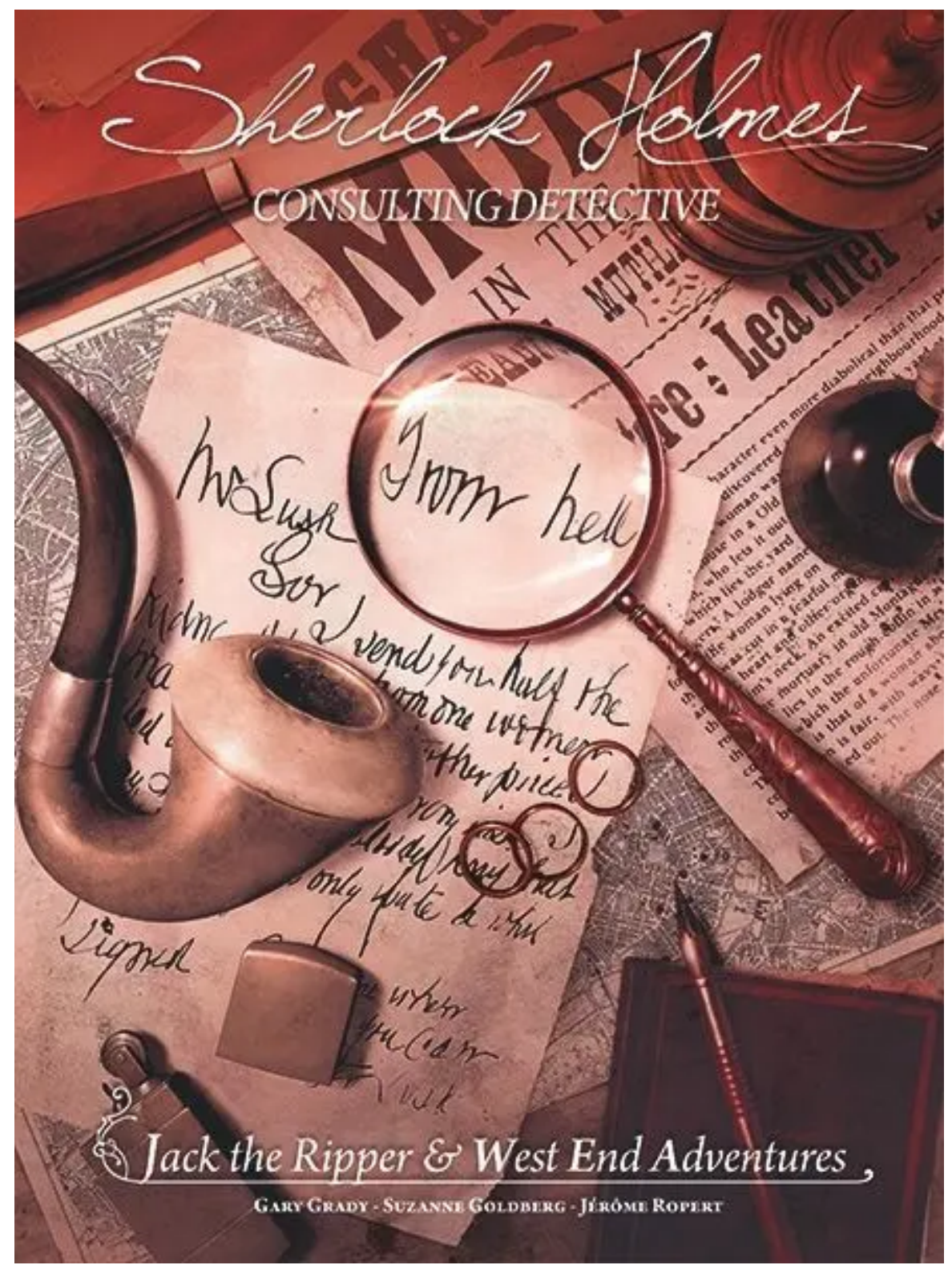

Image 08: Sherlock Holmes: Consulting Detective: Jack the Ripper \& West End Adventures (Creative Commons Attribution 3.0 Unported Licence)

The study of board games as media is still in its infancy. This year, Paul Booth published the first full-length study, Board Games as Media, arguing that we now have "an opportunity to explore the cultural messages communicated by board games [because] board games are an important artifact for reflecting on and analyzing cultural trends, historical antecedents, and thematic content in contemporary society" ${ }^{4}$. My own foray into 
board game studies has been a step in the direction of looking deeper into how that thematic content affects the understanding of problems in contemporary society, such as climate change. As board games continue to mature, we see more nuanced and thoughtprovoking treatment of serious subject matters in a medium once thought as the domain of simple fun. Every year at board game conventions and trade fairs, such as the Spielmesse Essen, we see ample of evidence for innovative designs that continue to push the boundaries of what is possible in board gaming. If you would like to follow that journey, I hope we will see each other at the fair.

\section{References}

1. See Gobet, Fernand, Jean Retschitzki and Alex de Voogt, Moves in Mind. The Psychology of Board Games, Hove: Psychology Press, 2012.

2. Woods, Stewart, Eurogames. The Design, Culture, and Play of Modern European Board Games, Jefferson (N.C.) \& London: McFarland \& Co., 2012, p. 110.

3. Arnaudo, Marco, Storytelling in the Modern Board Game. Narrative Trends from the late 1960s to Today, Jefferson (N.C.): McFarland \& Co., 2018, p. 32.

4. Booth, Paul, Board Games as Media, London: Bloomsbury Academic, 2021, p. 6. https://doi.org/10.5040/9781501357206.

SUGGESTED CITATION: Makai, Péter Kristóf: When Themes Come True. Why Board Games are like Theme Parks, in: KWI-BLOG, [https://blog.kulturwissenschaften.de/when-themes-come-true/], 18.10.2021

DOI: https://doi.org/10.37189/kwi-blog/20211018-0830 
This text is made available via DuEPublico, the institutional repository of the University of Duisburg-Essen. This version may eventually differ from another version distributed by a commercial publisher.

DOI: $\quad 10.37189 / \mathrm{kwi}-\mathrm{blog} / 20211018-0830$

URN: urn:nbn:de:hbz:464-20211018-112824-7 